\title{
Microencapsulation of plum (Prunus salicina Lindl.) phenolics by spray drying technology and storage stability
}

\author{
Yibin $\mathrm{LI}^{1,2}$, Baosha TANG ${ }^{1}$, Junchen $\mathrm{CHEN}^{1 *}$, Pufu LAI ${ }^{1}$
}

\begin{abstract}
To improve the stability of the phenolic extracts from plum fruit (Prunus salicina Lindl.), the microencapsulation conditions of spray drying were optimized by the response surface method. The Box-Behnken experimental results indicated the optimal conditions involved an inlet air temperature of $142.8{ }^{\circ} \mathrm{C}$, a core material content of $23.7 \%$ and a feed solids content of $11.7 \%$. The maximum microencapsulating efficiency was $87.7 \%$ at optimal conditions. Further, the physicochemical properties of the microcapsule powders were improved overall due to the addition of the coating agents. There were no statistically significant differences in phenolic content of the obtained microcapsules for the first 40 days of storage at $25^{\circ} \mathrm{C}$ in dark condition $(p>0.05)$, and the retention rate of total phenol remained above $85 \%$ after 60 days. Microcapsules can be potentially developed as a source of natural pigment or functional food based on the advantages of rich phenolic compounds and red color.
\end{abstract}

Keywords: Prunus salicina Lindl.; microencapsulation; phenolics; spray drying; storage stability; physicochemical properties.

Practical Application: Microencapsules of plum phenolics can be used as a source of natural pigment or functional food.

\section{Introduction}

Plum (Prunus salicina Lindl.) is one of the important fruits in the temperate zone. This fruit is widely cultivated in China, Japan, Spain, Chile, the United States, and other countries. Plum fruit presents high levels of phenolic compounds and anthocyanins, as well as strong antioxidant capacities (Bobrich et al., 2014; Lozano et al., 2009). Furthermore, plum polyphenols can inhibit colorectal aberrant crypt foci formation (Banerjee et al., 2016) and xanthine oxidase activities (Li et al., 2016). However, phenolic compounds are unstable and susceptible to oxidation, polymerization, condensation reaction when exposed to light, oxygen, or high temperatures, thus undermining their biological activity.

Microcapsule technology utilizes natural or synthetic polymeric materials to encapsulate solid, liquid, and even gaseous substances to form minute particles with semipermeable or sealed capsules. Microencapsulation is used for protecting a bioactive compound from light, oxygen, or other unfavorable conditions and improving stability (Gonçalves et al., 2017). Therefore, microencapsulation methods have been performed to store phenolic compounds extracted from vegetables or fruits (Çam et al., 2014; Paini et al., 2015).

Spray drying, a common industrial encapsulation technique, has been presented as an efficient method for protecting bioactive compounds from possible physical and chemical interactions with the external environment, thus, allowing a longer shelf life and wider industrial application. Moreover, spray drying provides rapid evaporation of water and maintains the low temperature in the particles (Busch et al., 2017). Several studies were performed using spray drying as microencapsulation technology for phenolic extracts from different plant sources, for example, phenolic compounds of olive pomace (Paini et al., 2015) and jaboticaba peel extracts (Silva et al., 2013). However, microencapsulation of phenolic extracts from plum using spray drying has not been performed yet.

The objective of this work was to obtain the microencapsulation powder of phenolic extract from plum fruit by optimizing the spray drying parameters. The physicochemical characteristics and storage stability of powders were determined after encapsulation.

\section{Materials and methods}

\subsection{Plant materials}

The plum of Prunus salicina Lindl. cv. Furong was collected from Yongtai County of Fujian Province, China. After picking and cleaning, the plums pits were removed and the pulps were dried to a moisture content of less than $15 \%$ with hot air at $50^{\circ} \mathrm{C}$. The dried pulps were milled and sieved $(0.5$ and $2.0 \mathrm{~mm}$ particle size) then stored at $-20^{\circ} \mathrm{C}$ refrigerator in the dark.

\subsection{Chemicals}

Gallic acid was purchased from Shanghai Yuanye Biotechnology Co., Ltd.. Maltodextrin (dextrose equivalence 15) was sourced from Tang Ye (Tianjin) Food Co., Ltd., China. Beta-cyclodextrin was obtained from Shanghai Chemical Reagent Co., Ltd, China. Arabic gum was purchased from Shanghai Quan Wang Biological Technology Co., Ltd.. All other organic solvents used in the study were analytical grade. 


\subsection{Extraction of phenolics}

Phenolics of plums were extracted with $61 \%$ ethanol by applying previously optimized conditions at a ultrasonic power of $420 \mathrm{~W}$, and an extraction temperature of $59^{\circ} \mathrm{C}$ for $47 \mathrm{~min}$ (Li et al., 2016). Twenty grams of plum samples were placed in a $1 \mathrm{~L}$ beaker and mixed with $200 \mathrm{~mL}$ of $61 \%$ ethanol $(w / v)$. The extraction process was performed in an ultrasonic bath (KQ-600DV, 40 kHz, Kunshan Ultrasonic Instrument Co. Jiangsu, China). After ultrasonic extraction, the mixture was filtered (Whatman No. 1 paper). The filtrate was condensed to $17 \%$ solid content with a vacuum rotary evaporator (Senco-GG17, Shanghai Shenke Science and Technology Co., Ltd., China) at $0.09 \mathrm{MPa}, 45^{\circ} \mathrm{C}$. The phenolic extracts of plum were stored in $-20{ }^{\circ} \mathrm{C}$ for further use.

\subsection{Encapsulation of propolis by spray drying}

In previous studies, the effects of different coating agents and their combinations on the microencapsulation efficiency of plum phenolics were discussed. Finally spray drying of phenolic extracts was performed using maltodextrins, beta-cyclodextrin and arabic gum as coating agents. The ratio of the coating agents was maltodextrin: beta-cyclodextrin: arabic gum $=7$ : 2: $1(w / w / w)$. The microencapsulation process was performed using a laboratory-scale spray dryer (Shiyuan Mini Spray Dryer SY6000, China) under the following operational conditions: atomization pressure $90 \mathrm{MPa}$, feed flow rate $550 \mathrm{~mL} / \mathrm{h}$, air flow rate $330 \mathrm{~m}^{3} / \mathrm{h}$, and inlet-air temperature ranged from $110{ }^{\circ} \mathrm{C}$ to $150^{\circ} \mathrm{C}$. Under these conditions the outlet-air temperatures ranged from $88{ }^{\circ} \mathrm{C}$ to $94{ }^{\circ} \mathrm{C}$. The spray drying powders were packed with aluminum foil bags and storied at $-20{ }^{\circ} \mathrm{C}$ for further use.

\subsection{Experimental design}

On the basis of the previous single factor test, a response surface method (RSM) was used to evaluate the influence of three independent variables on the microencapsulating efficiency of total phenolics. The independent variables were air inlet temperature $\left({ }^{\circ} \mathrm{C}, \mathrm{X}_{1}\right)$, Core content $\left(\%, \mathrm{X}_{2}\right)$ and Feed solids concentration $\left(\%, \mathrm{X}_{3}\right)$. The experimental design for the Box-Behnken Design was performed in random order and consisted of 17 combinations including five replicates at central point (Table 1). In order to obtain the regression coefficients, an analysis of variance (ANOVA) was carried out using the Design-Expert.V8.0.6.1 software (State-Ease lnc., Minneapolis, MN, USA). Experimental data were fitted to a second-order polynomial model where multiple regression analysis and ANOVA were used to determine fitness of the model and optimal conditions for investigated responses. All of the treatments were performed in triplicate.

\subsection{Determination of total phenolic content}

Total phenolic content was evaluated using the Folin-Ciocalteu assay (Li et al., 2016). An amount of $100 \mathrm{mg}$ of phenolic powder was accurately weighed and dissolved in $5 \mathrm{ml}$ deionized water. Then the mixture was agitated using a vortex shaker (QL-861, Haimen Qilinbell Instrument Manufacturing Co., Ltd, China) for $1 \mathrm{~min}$ and filtered with microfilter $(0.45 \mu \mathrm{m}) .2 .5 \mathrm{~mL}$ diluted Folin-Ciocalteu reagent $(10 \%, \mathrm{v} / \mathrm{v})$ was added to $200 \mu \mathrm{L}$ of filtrate in a capped glass tube. After $2 \mathrm{~min}$ of incubation in the dark at room temperature, $2 \mathrm{~mL}$ of aqueous sodium carbonate $(7.5 \%, \mathrm{w} / \mathrm{v})$ was added to the mixture. And then it was made up $10 \mathrm{ml}$ by adding distilled water. After gentle vibration, the mixture was placed in a water bath at $50^{\circ} \mathrm{C}$ for $30 \mathrm{~min}$ and then rapidly cooled down to room temperature $\left(25^{\circ} \mathrm{C}\right)$. Absorbance was measured at $765 \mathrm{~nm}$ using a UV-vis spectrophotometer (756P, Shanghai Spectrum Instruments Co., Ltd., China). Total phenolic content of spray-dried phenolic powder was expressed as mg GAE (gallic acid equivalent) per gram of dried weight.

\subsection{Surface phenolic content of microencapsules}

Surface phenolic content was determined following the method of Cilek et al. (2012). An amount of $100 \mathrm{mg}$ of microcapsules were dispersed with $5 \mathrm{ml}$ of ethanol for $3 \mathrm{~min}$. The mixture was filtered with microfilter $(0.45 \mu \mathrm{m})$ and the total phenolic content of the filtrate was determined. The amounts of surface phenolic compounds were determined and quantified with the same method described in total phenolic content section.

\subsection{Efficiency and yield of microencapsulation}

Microencapsulating efficiency was calculated as the ratio of encapsulated phenolic content to total phenolic content. The microencapsulating yield was the ratio of the mass of the microcapsules obtained at the end of the process to the mass of the initial substances (solids of plum extracts and coating agents). Microencapsulating efficiency and yield of microcapsules were calculated according to Equations (1) and (2), respectively (Cilek et al., 2012; Venil et al., 2016).

Table 1. The experimental design and results for response surface methodology*.

\begin{tabular}{ccccc}
\hline Run & $\mathrm{X}_{1}\left({ }^{\circ} \mathrm{C}\right)$ & $\mathrm{X}_{2}(\%)$ & $\mathrm{X}_{3}(\%)$ & $\begin{array}{c}\text { Microencapsulating } \\
\text { efficiency }(\%)\end{array}$ \\
\hline 1 & 130 & 20 & 10 & $85.7 \pm 1.5$ \\
2 & 130 & 15 & 15 & $83.4 \pm 2.0$ \\
3 & 130 & 25 & 15 & $85.1 \pm 1.8$ \\
4 & 150 & 20 & 15 & $86.4 \pm 1.0$ \\
5 & 150 & 25 & 10 & $87.4 \pm 1.4$ \\
6 & 110 & 20 & 5 & $77.7 \pm 1.4$ \\
7 & 110 & 20 & 15 & $78.3 \pm 2.3$ \\
8 & 130 & 20 & 10 & $86.2 \pm 1.6$ \\
9 & 150 & 20 & 5 & $83.6 \pm 0.7$ \\
10 & 130 & 20 & 10 & $85.0 \pm 1.8$ \\
11 & 130 & 15 & 5 & $80.2 \pm 1.1$ \\
12 & 130 & 20 & 10 & $85.6 \pm 1.7$ \\
13 & 110 & 15 & 10 & $76.4 \pm 1.9$ \\
14 & 150 & 15 & 10 & $81.5 \pm 2.0$ \\
15 & 130 & 25 & 5 & $84.8 \pm 1.6$ \\
16 & 110 & 25 & 10 & $79.0 \pm 1.4$ \\
17 & 130 & 20 & 10 & $86.3 \pm 1.9$ \\
\hline${ }^{*} \mathrm{X}_{1}=$ Air inlet temperature; $\mathrm{X}_{2}=$ Core content; $\mathrm{X}_{3}=$ Feed solids concentration; Mean
\end{tabular}

values $(n=3) \pm$ S.D. 
Efficiency $(\%)=\left(1-\frac{\text { Phenolics on microcapsule surface }}{\text { Total phenolics of microcapsule }}\right) \times 100$

Yield $(\%)=\frac{\text { Mass of microcapsules }(g)}{\text { Total mass of initial subs } \tan \text { ces }(g)} \times 100$

\subsection{Physicochemical characterization of powders}

Moisture content: Powder was dried at $105^{\circ} \mathrm{C} \pm 2{ }^{\circ} \mathrm{C}$ until a constant weight, and moisture content was calculated based on the loss in weight between before and after drying.

Water activity: The water activity $\left(a_{w}\right)$ values of powders were measured with a water activity measurement device (HD-3A, Wuxi Huake Instrument Co., Ltd., China).

Bulk density: The bulk density of the phenolic powders was determined by pouring approximately $5 \mathrm{~g}$ of the powder into a $10 \mathrm{~mL}$ graduated cylinder. The volume occupied by the sample was recorded and bulk density was calculated by dividing the mass of the powder by the volume occupied in the cylinder (Paini et al., 2015).

Angle of repose: The angle of repose was determined by pouring the powder from a funnel (dia. $1 \mathrm{~cm}$ ) to the surface plate. A funnel was clamped with its tip $7 \mathrm{~cm}$ above the surface. The tangent of the angle of repose was the ratio of the height of the heap of powder to the semi-diameter of the base of the heap of powder (Kaur et al., 2015).

Color analysis: The color of the samples was carried out with a colorimeter (NS810, Shenzhen 3NH Technology Co., Ltd., China) and reported in CIE $L^{*}, a^{*}, b^{*}$ values. $L^{*}$ denotes the degree of lightness on 0-100 scale from black to white, $a^{*}$ is the degree of redness $(+)$ to greenness $(-)$, and $b^{*}$ is the degree of yellowness $(+)$ to blueness (-) (Simon-Brown et al., 2016). The instrument was standardized by a white tile before the measurements. All analyses were performed in triplicate.
Scanning electron microscopy: Morphological characteristics of the microencapsulated powders were observed using a JSM-6380LV scanning electron microscope (Japan).

\subsection{Storage stability}

During storage tests, microcapsules and phenolic powder (non-encapsulated) were sealed with aluminum foil bags respectively and were stored in a $25^{\circ} \mathrm{C}$ incubator for 2 months. The total phenol retention of the samples was analyzed on the days 10, 20, 30, 40, 50 and 60 during storage.

\section{Results and discussion}

\subsection{Fitting the response surface models}

The three factor and three level response surface analysis was designed by selecting the inlet air temperature, the core material content, the feed solids content as independent variables, and the microencapsulating efficiency as the response value. The results of the test and the results were shown in Table 1. By using Design-Expert V8.06 software, the response surface regression analysis of the experimental data was carried out, and the simulation equations of the microencapsulating efficiency and the dependent variables were obtained:

$Y=85.77+3.44 X_{1}+1.82 X_{2}+0.86 X_{3}+0.81 X_{1} X_{2}+0.53 X_{1} X_{3}-$ $0.72 X_{2} X_{3}-3.3 X_{1}^{2}-1.41 X_{2}^{2}-0.98 X_{3}^{2}$

In order to test the validity of the regression equation, the variance analysis and the model analysis were carried out (ANOVA, Table 2). It could be seen from Table 2 that the $p<0.0001$ of the model showed that the equation of the two order was extremely significant. Lack of fit $(p=0.6161>0.05)$ was not significant, which suggested that the regression equation fit o the test accuracy and small error. The coefficient of determination was $R^{2}=0.9907$,

Table 2. Analysis of variance (ANOVA) for the regression model.

\begin{tabular}{|c|c|c|c|c|c|}
\hline Source & Sum of Squares & $\mathrm{DF}$ & Mean Square & $F$-Value & $p$-Value \\
\hline Model & 196.0 & 9 & 21.8 & 83.3 & $<0.0001$ \\
\hline $\mathrm{X}_{1}$ & 94.7 & 1 & 94.7 & 362.0 & $<0.0001$ \\
\hline $\mathrm{X}_{2}$ & 26.5 & 1 & 26.5 & 101.5 & $<0.0001$ \\
\hline $\mathrm{X}_{3}$ & 6.0 & 1 & 6.0 & 22.8 & 0.0020 \\
\hline $\mathrm{X}_{1} \mathrm{X}_{2}$ & 2.7 & 1 & 2.7 & 10.2 & 0.0153 \\
\hline $\mathrm{X}_{1} \mathrm{X}_{3}$ & 1.1 & 1 & 1.1 & 4.2 & 0.0792 \\
\hline $\mathrm{X}_{2} \mathrm{X}_{3}$ & 2.1 & 1 & 2.1 & 7.9 & 0.0263 \\
\hline $\mathrm{X}_{1}^{2}$ & 46.0 & 1 & 46.0 & 175.8 & $<0.0001$ \\
\hline $\mathrm{X} 2^{2}$ & 8.3 & 1 & 8.3 & 31.9 & 0.0008 \\
\hline $\mathrm{X}_{3}^{2}$ & 4.0 & 1 & 4.0 & 15.4 & 0.0057 \\
\hline Residual & 1.8 & 7 & 0.3 & & \\
\hline Lack of Fit & 0.6 & 3 & 0.2 & 0.7 & 0.6055 \\
\hline Pure Error & 1.2 & 4 & 0.3 & & \\
\hline $\begin{array}{c}\text { Cor Total } \\
R^{2}=0.9907 ; \\
R_{A d j}^{2}=0.9789\end{array}$ & 197.9 & 16 & & & \\
\hline
\end{tabular}


which indicated the regression model fit well and the variation of the response value was $99.07 \%$ from the selected variables. The adjustment coefficient of the model was $R_{\text {Adj }}^{2}=0.9789$, which showed that had excellent predictability and the actual value was close to the predicted value. Therefore, the regression model was feasible, which was suitable to analyze and predict the microencapsulation parameters of spray drying from plum fruit extract.

\subsection{Response surface analysis of interaction between different factors}

According to the regression equation, the interaction between three factors, including the inlet air temperature, the core material content and the feed solids concentration, was analyzed (Figure 1).

As shown in Figure 1A, the response surface was quite steep, indicating a significant interaction between the inlet air temperature and the core material content. The effect of inlet air temperature on encapsulating efficiency was more than that of core material content, which was consistent with the results of the above ANOVA analysis. It can be seen from Figure 1B that the polyphenol encapsulating efficiency increased firstly and then decreased slowly as the inlet air temperature or the feed solids concentration increased. Figure $1 \mathrm{C}$ presented that the interaction between the core content and the feed solids concentration was significant and the core content had a greater effect on the microencapsulating efficiency of phenolic extracts.

\subsection{Optimization of microencapsulation conditions and verification of model}

The optimum parameters of plum extract microencapsulation were obtained by means of mathematic model. The microencapsulating efficiency was $87.7 \%$ when the optimum process parameters of spray drying were as follows: inlet air temperature $142.8^{\circ} \mathrm{C}$, core material $23.7 \%$, and feed solids content $11.7 \%$.

To validate the constructed mathematical models, a spray-drying experiment was carried out at the optimal conditions for three parallel experiments. Considering the actual operation, the optimum parameters of spray drying were modified to the inlet air temperature of $143^{\circ} \mathrm{C}$, the core material content of $23.7 \%$ and feed solids content of $11.7 \%$. Under these conditions, the microencapsulating efficiency of the plum extract was $89.3 \%$. The error between the actual value and the predicted value was $1.8 \%$, which indicated that the constructed mathematical model appropriately explained the actual microencapsulation process of the phenolic extract from plum.

\subsection{Physicochemical properties of microencapsulated powder}

The physicochemical properties of the microcapsules (Figure 2) produced under the optimized spray dryer operating conditions and phenolic powder (non-encapsulated) prepared by spray drying without using any coating agents were detailed in Table 3.

\section{Moisture, $a_{w}$ and yield}

Table 3 indicated that the spray drying yield of phenolic extract significantly increased after microencapsulation, and the moisture content and water activity of the product obviously decreased, which showed that the coating agents improved the yield and quality of the spray dried powder from plum extracts. Similar results were also reported by Peng et al. (2013).
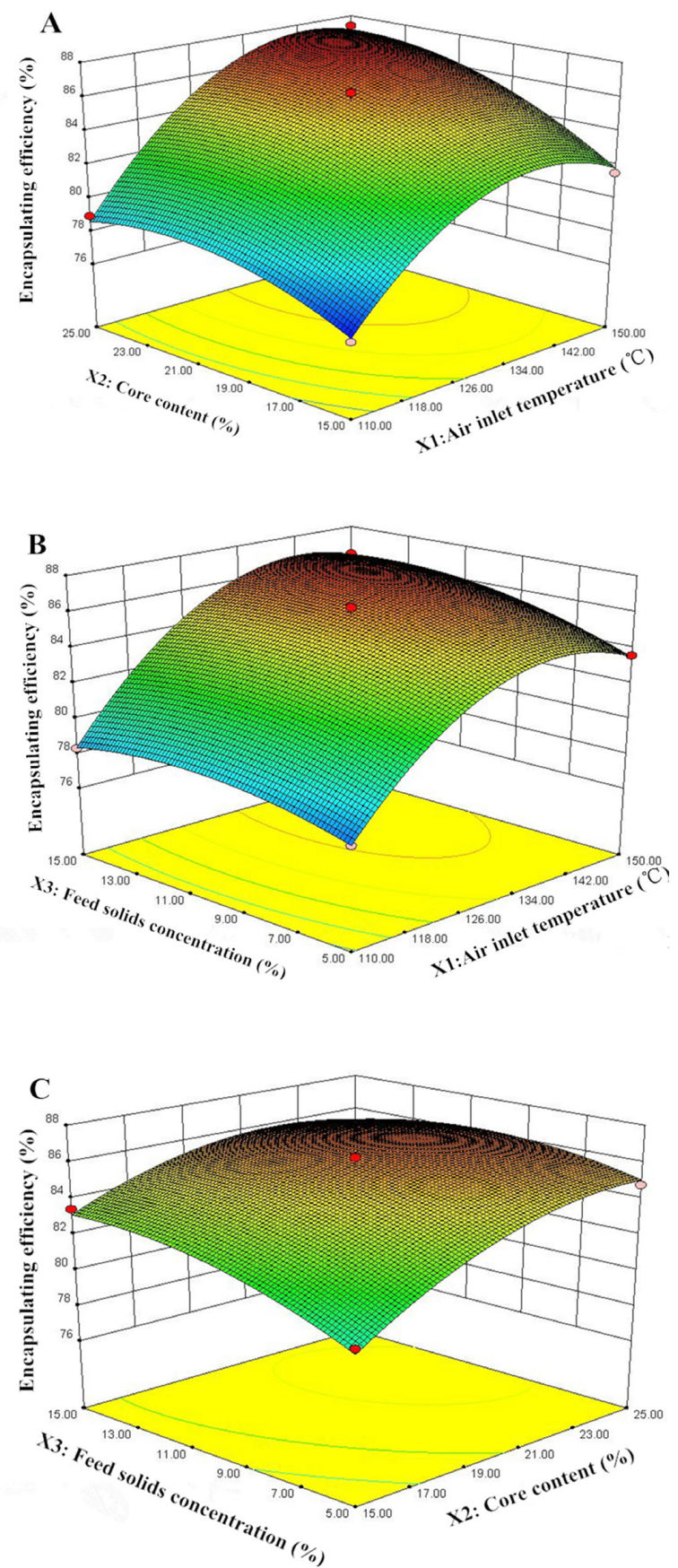

Figure 1. Response surface plots for encapsulating efficiency of phenolic compounds as a function of (A) inlet air temperature to core content (feed solids concentration $=10 \%$ ); $(\mathrm{B})$ inlet air temperature to feed solids concentration (core content $=20 \%$ ); $(C)$ core content to feed solids concentration (air inlet temperature $=130{ }^{\circ} \mathrm{C}$ ). 

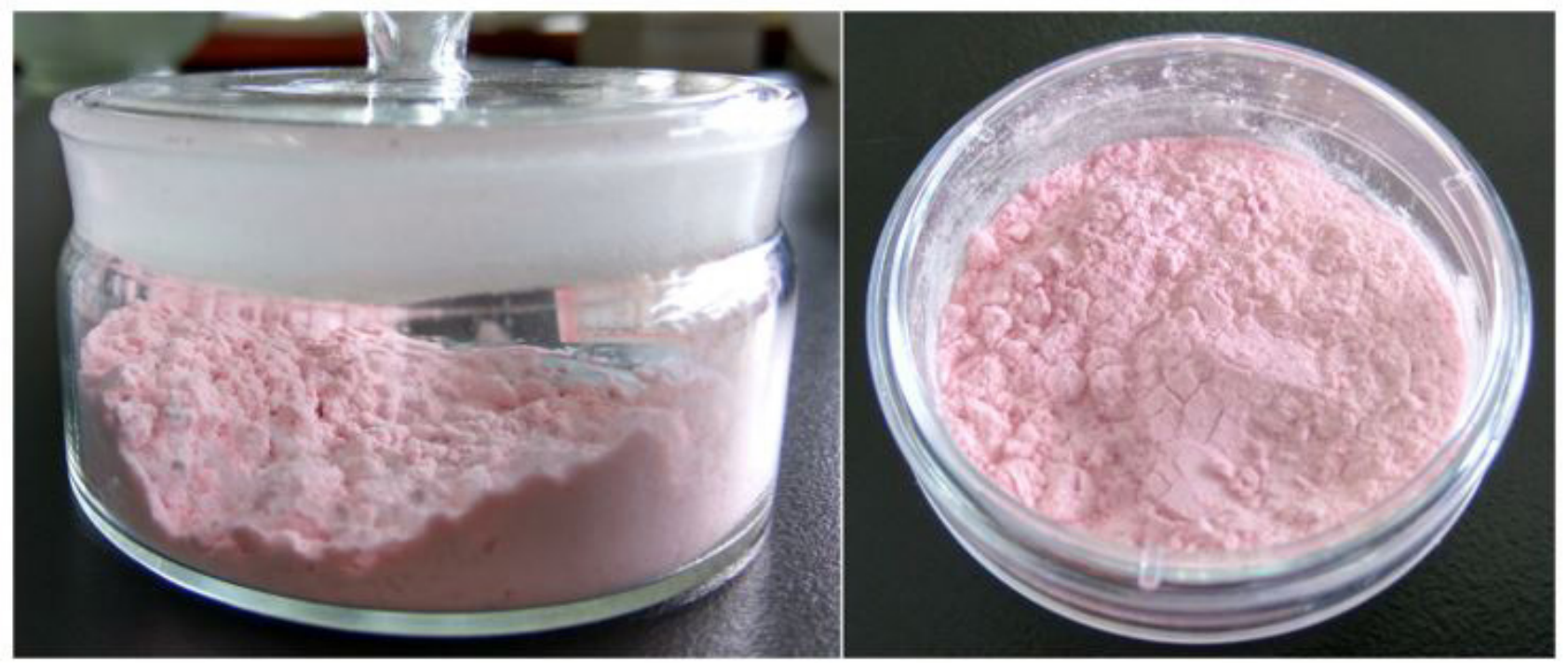

Figure 2. Microencapsulated powders of phenolic extract prepared by spray drying.

Table 3. Physicochemical properties of microencapsulated powder (MP) and phenolics powder (non-encapsulated) (PP)a .

\begin{tabular}{|c|c|c|c|c|c|c|c|c|c|}
\hline \multirow[b]{2}{*}{ Items } & \multirow[b]{2}{*}{ Moisture (\%) } & \multirow[b]{2}{*}{$a_{w}$} & \multirow[b]{2}{*}{ Yield (\%) } & \multirow{2}{*}{$\begin{array}{l}\text { Bulk density } \\
\quad\left(\mathrm{g} \cdot \mathrm{mL}^{-1}\right)\end{array}$} & \multirow{2}{*}{$\begin{array}{l}\text { Angle of } \\
\text { repose }\left(^{\circ}\right)\end{array}$} & \multicolumn{3}{|c|}{ Color $^{\mathrm{b}}$} & \multirow{2}{*}{$\begin{array}{c}\text { Total } \\
\text { phenol (mg } \\
\text { GAE/g) }\end{array}$} \\
\hline & & & & & & $L^{*}$ & $a^{*}$ & $b^{*}$ & \\
\hline $\mathrm{PP}$ & $5.4 \pm 0.3$ & $0.4 \pm 0.1$ & $59.6 \pm 2.1$ & $0.6 \pm 0.1$ & $55.5 \pm 3.6$ & $55.2 \pm 1.4$ & $22.3 \pm 1.2$ & $3.9 \pm 0.2$ & $182.8 \pm 4.2$ \\
\hline
\end{tabular}

${ }^{\text {aD }}$ ata are presented as the mean \pm SD $(n=3)$. MP represents the microencapsulated powder prepared by the above optimum conditions of spray drying, and PP represents phenolic powder (non-encapsulated) prepared by spray drying without using any coating agents; ${ }^{\text {bn }}$ the CIE-Lab system, $L^{\star}$ denotes lightness on $0-100$ scale from black to white; $a^{\star}$, $(+)$ red or (-) green; and $b^{*},(+)$ yellow or $(-)$ blue.

\section{Bulk density and angle of repose}

Bulk density of the spray-dried microparticles is the density of powder when packed or stacked in bulk, and the angles of repose are used to describe the fluidity of powder. Table 3 showed that microencapsulation improved the fluidity of the powder as indicated by the decreased angles of repose and reduces the bulk density. Similar findings were observed by Fazaeli et al. (2012). The bulk density and fluidity of the microcapsule product were related to the nature of the coating material used for embedding (Bhusari et al., 2014).

\section{Color}

Color parameters, including $L^{*}, a^{*}$, and $b^{*}$ values of the spray-dried powder were presented in Table 3 . An increase in $L^{*}$ value was as a result of the addition of the coating agents. This observation was similar to that made by Peng et al. (2013). $a^{*}$ values and $b^{*}$ values of microparticles with coating agents were significantly lower than those of the powder without coating agents, thus decreasing the redness and yellowness of powder because of the addition of the coating agents. The observation was in agreement with the result reported by Bhusari et al. (2014). The evaluation of $a^{\star}$ parameters for the microparticles containing plum extract was related to the red color and may be associated with the content of anthocyanins present in the sample. Similar trend was found by Carvalho et al. (2016). The changes in color parameters were attributed to the addition of coating agents and were associated with variation in phenols and anthocyanins (Peng et al., 2013).

\section{Total phenol}

Table 3 showed that both spray-dried powders were rich sources of phenolic compounds. But the microcapsules were lower on the indicator, which might be that the coating agents reduced the concentration of the active ingredient in the microcapsule powder.

\section{Morphology of microencapsulated powder}

The surface morphology of microcapsules is an important index for the quality of microcapsules. The surface structure of microcapsules not only affects the microencapsulation effect, but also is closely related to physicochemical properties of microcapsules, such as fluidity and dispersibility (Santana et al., 2013; Çam et al., 2014). The surface microstructure observed in the scanning electron microscope of phenolic microcapsules from plums was shown in Figure 3 with a level of magnification of $1,000 \times$ and 2,000x. Most of the microencapsulated particles were 

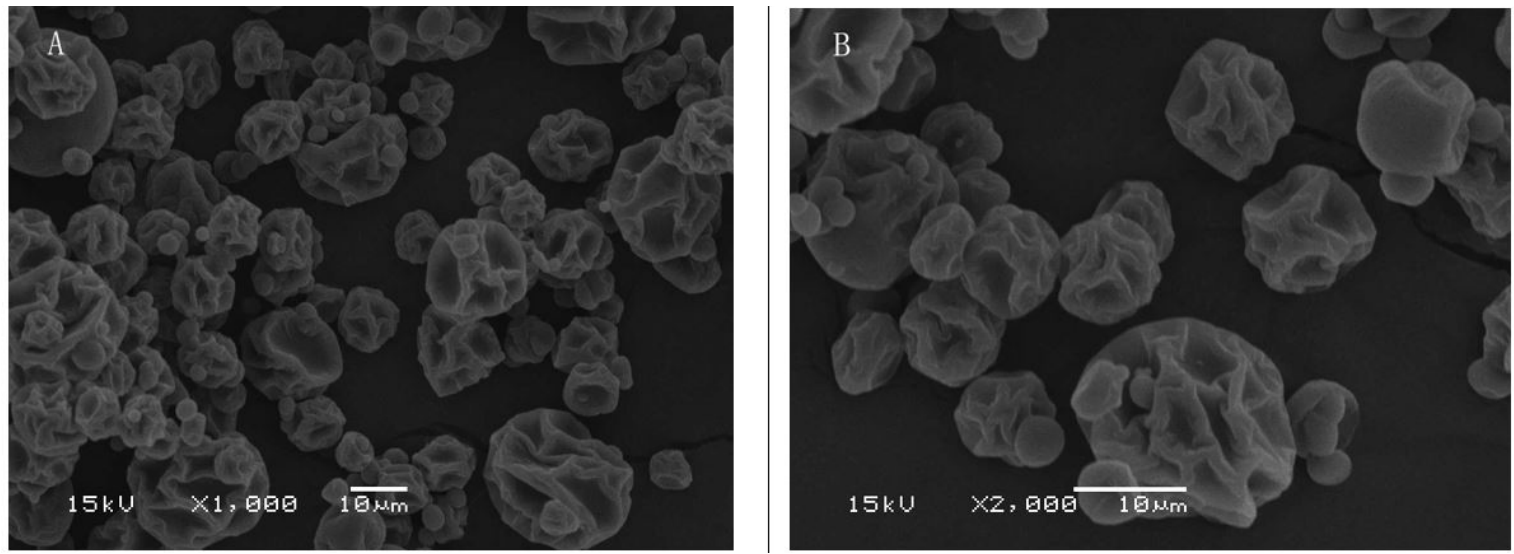

Figure 3. Scanning electron microstructure of microencapsulated powder from plum extract. (A) $\times 1000$; (B) $\times 2000$.

spherical shapes on the whole, and particles had a complete surface structure with no cracks or collapses, which suggested that the microencapsulation of powder may be favourable and effective. The surface of the microcapsule particles was wrinkled, which is one of the reasons for the poor fluidity of the microcapsules. This is consistent with other microcapsules prepared by spray drying (Fernandes et al., 2014).

\subsection{Storage stability}

In order to determine the storage stability of microcapsules as well as to evaluate the protective effects of coating material on phenolics, the microcapsules and phenolic powder (non-encapsulated) prepared by spray drying without using any coating material were stored at $25^{\circ} \mathrm{C}$ for 60 days. Figure 4 obviously showed that the phenolic microcapsules were more stable than the phenolic powder (non-encapsulated) during storage. There were no significant differences in the total phenol content of the microcapsules within the first 40 days of storage $(p>0.05)$. And after 60 days storage at $25^{\circ} \mathrm{C}$, the total phenol retention rate of the microcapsules was still greater than $85 \%$. However, $36.75 \%$ and statistically significant loss in phenolic content of the phenolic powder (non-encapsulated) was observed after 60 days storage at $25^{\circ} \mathrm{C}$. The results indicated that the filmforming property of coating material and capsule membrane compactness of the microcapsule product were well, which could resist the destructive effect of the adverse environment and reduce the influence of the external conditions on the stability of phenolic compounds.

This was in agreement with the reports of other researchers who had evaluated the effect of microencapsulation by spray drying on phenolics. Santiago et al. (2016) observed that anthocyanin retention in microcapsules produced by spray drying of pomegranate juice was equivalent to $90 \%$ and $60 \%$ after being stored at $25^{\circ} \mathrm{C}$ for 90 and 120 days, respectively. Çam et al. (2014) evaluated the stability of the microcapsules and phenolics powder (non-encapsulated) obtained by spray drying without using any coating material from Pomegranate peel stored at $4{ }^{\circ} \mathrm{C}$ for 3 months, these authors observed phenolic microcapsules are more stable than the phenolics powder. Only $18 \%$ decrease in anthocyanin content of the microcapsules obtained from

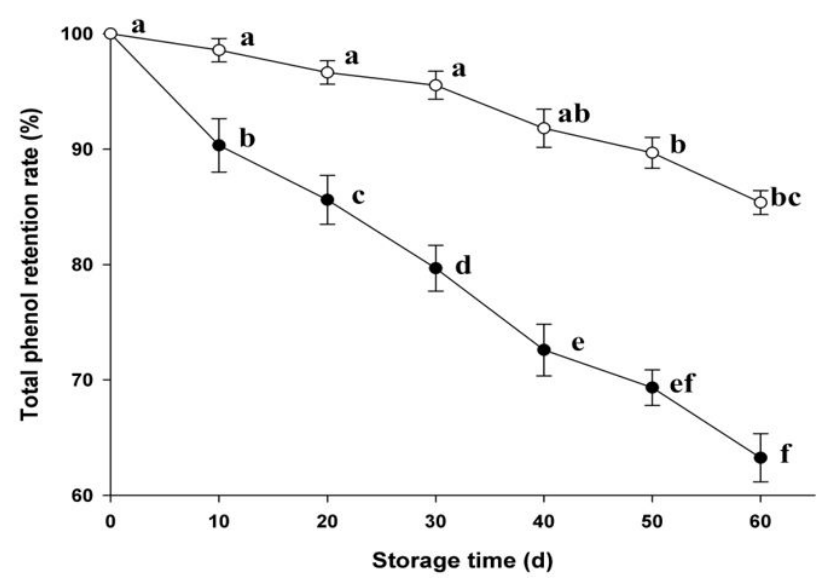

Figure 4. Storage stability of microcapsules ( $($ ) and phenolic powder $(\bullet)$. (Values represent the mean \pm standard deviation $(n=3)$. Different letters after mean values indicate significant differences among the storage periods of samples $(p<0.05)$.

Guarcinia indica was observed at the end of 12 weeks storage at $25^{\circ} \mathrm{C}$ (Nayak \& Rastogi, 2010).

\section{Conclusions}

The microencapsulating conditions of the spray drying from plum fruit (Prunus salicina Lindl.) phenolics were optimized by a Box-Behnken experiment design of three variables. Using the response surface method, the optimum conditions of spray drying were the inlet air temperature of $143^{\circ} \mathrm{C}$, the core material content of $23.7 \%$ and feed solids content of $11.7 \%$. Although total phenol content of microcapsules decreased, overall the physicochemical properties of the spray-dried powders were improved after adding the coating agents. Phenolic components of the microcapsules did not lose significantly in the first 40 days of storage under the condition of $25^{\circ} \mathrm{C}$ dark storage, and the retention rate of total phenol remained above $85 \%$ after 60 days. The results clearly indicated that the storage stability of microencapsulated powder was better than that of phenolic powder (non-encapsulated). Therefore, microencapsulated 
powder of plum extract can be considered as a potential source of natural pigment or functional food due to the advantages of rich phenolic compounds and red color. Future studies are necessary to investigate the interaction of plum phenolics with other food components.

\section{Acknowledgements}

The authors gratefully thanks the financial support of this study by the public service sectors (agriculture) project of China Agricultural Ministry (201503142), and the science and technology innovation team PI project (2016PI-3) and young talents project (YC2016-13) of Fujian Academy of Agricultural Sciences. At the same time, thank you for the support of Fujian Key Laboratory of Agricultural Product (Food) Processing.

\section{References}

Banerjee, N., Kim, H., Talcott, S. T., Turner, N. D., Byrne, D. H., \& Mertenstalcott, S. U. (2016). Plum polyphenols inhibit colorectal aberrant crypt foci formation in rats: potential role of the mir-143/ protein kinase $\mathrm{b} / \mathrm{mammalian}$ target of rapamycin axis. Nutrition Research, 36(10), 1105-1113. PMid:27865352. http://dx.doi. org/10.1016/j.nutres.2016.06.008.

Bhusari, S. N., Muzaffar, K., \& Kumar, P. (2014). Effect of carrier agents on physical and microstructural properties of spray dried tamarind pulp powder. Powder Technology, 266, 354-364. http:// dx.doi.org/10.1016/j.powtec.2014.06.038.

Bobrich, A., Fanning, K. J., Rychlik, M., Russell, D., Topp, B., \& Netzel, M. (2014). Phytochemicals in japanese plums: impact of maturity and bioaccessibility. Food Research International, 65(Part A), 20-26. http://dx.doi.org/10.1016/j.foodres.2014.06.030.

Busch, V. M., Pereyra-Gonzalez, A., Šegatin, N., Santagapita, P. R., Ulrih, N. P., \& Buera, M. P. (2017). Propolis encapsulation by spray drying: characterization and stability. Lebensmittel-Wissenschaft + Technologie, 75, 227-235. http://dx.doi.org/10.1016/j.lwt.2016.08.055.

Çam, M., İçyer, N. C., \& Erdoğan, F. (2014). Pomegranate peel phenolics: microencapsulation, storage stability and potential ingredient for functional food development. Lebensmittel-Wissenschaft + Technologie, 55(1), 117-123. http://dx.doi.org/10.1016/j.lwt.2013.09.011.

Carvalho, A. G. D. S., Machado, M. T. D. C., Silva, V. M. D., Sartoratto, A., \& Hubinger, M. D. (2016). Physical properties and morphology of spray dried microparticles containing anthocyanins of jussara (euterpe edulis martius) extract. Powder Technology, 294, 421-428. http://dx.doi.org/10.1016/j.powtec.2016.03.007.

Cilek, B., Luca, A., Hasirci, V., Sahin, S., \& Sumnu, G. (2012). Microencapsulation of phenolic compounds extracted from sour cherry pomace: effect of formulation, ultrasonication time and core to coating ratio. European Food Research and Technology, 235(4), 587-596. http://dx.doi.org/10.1007/s00217-012-1786-8.

Fazaeli, M., Emam-Djomeh, Z., Ashtari, A. K., \& Omid, M. (2012). Effect of spray drying conditions and feed composition on the physical properties of black mulberry juice powder. Food and Bioproducts Processing, 90(4), 667-675. http://dx.doi.org/10.1016/j.fbp.2012.04.006.

Fernandes, R. V., Borges, S. V., \& Botrel, D. A. (2014). Gum arabic/starch/ maltodextrin/inulin as wall materials on the microencapsulation of rosemary essential oil. Carbohydrate Polymers, 101(101), 524-532. PMid:24299808. http://dx.doi.org/10.1016/j.carbpol.2013.09.083.
Gonçalves, A., Estevinho, B. N., \& Rocha, F. (2017). Design and characterization of controlled-release vitamin a microparticles prepared by a spray-drying process. Powder Technology, 305, 411417. http://dx.doi.org/10.1016/j.powtec.2016.10.010.

Kaur, P., Singh, S. K., Garg, V., Gulati, M., \& Vaidya, Y. (2015). Optimization of spray drying process for formulation of solid dispersion containing polypeptide-k powder through quality by design approach. Powder Technology, 284, 1-11. http://dx.doi.org/10.1016/j.powtec.2015.06.034.

Li, Y., Lai, P., Chen, J., Shen, H., Tang, B., Wu, L., \& Weng, M. (2016). Extraction optimization of polyphenols, antioxidant and xanthine oxidase inhibitory activities from Prunus salicina Lindl. Food Science and Technology, 36(3), 520-525. http://dx.doi.org/10.1590/1678457X.0022.

Lozano, M., Vidalaragón, M. C., Hernández, M. T., Ayuso, M. C., Bernalte, M. J., García, J., \& Velardo, B. (2009). Physicochemical and nutritional properties and volatile constituents of six japanese plum (prunus salicina lindl.) cultivars. European Food Research and Technology, 228(3), 403-410. http://dx.doi.org/10.1007/s00217-008-0946-3.

Nayak, C. A., \& Rastogi, N. K. (2010). Effect of selected additives on microencapsulation of anthocyanin by spray drying. Drying Technology, 28(12), 1396-1404. http://dx.doi.org/10.1080/073739 37.2010.482705.

Paini, M., Aliakbarian, B., Casazza, A. A., Lagazzo, A., Botter, R., \& Perego, P. (2015). Microencapsulation of phenolic compounds from olive pomace using spray drying: a study of operative parameters. Lebensmittel-Wissenschaft + Technologie, 62(1), 177-186. http:// dx.doi.org/10.1016/j.lwt.2015.01.022.

Peng, Z., Li, J., Guan, Y., \& Zhao, G. (2013). Effect of carriers on physicochemical properties, antioxidant activities and biological components of spray-dried purple sweet potato flours. LebensmittelWissenschaft + Technologie, 51(1), 348-355. http://dx.doi.org/10.1016/j. lwt.2012.09.022.

Santana, A. A., Oliveira, R. A., Pinedo, A. A., Kurozawa, L. E., \& Park, K. J. (2013). Microencapsulation of babassu coconut milk. Food Science and Technology, 33(4), 737-744. http://dx.doi.org/10.1590/ S0101-20612013000400020.

Santiago, M. C. P. A., Nogueira, R. I., Paim, D. R. S. F., Gouvêa, A. C. M. S., Godoy, R. L. O., Peixoto, F. M., Pacheco, S., \& Freitas, S. P. (2016). Effects of encapsulating agents on anthocyanin retention in pomegranate powder obtained by the spray drying process. Lebensmittel-Wissenschaft + Technologie, 73, 551-556. http://dx.doi. org/10.1016/j.lwt.2016.06.059.

Silva, P. I., Stringheta, P. C., Teófilo, R. F., \& Oliveira, I. R. N. (2013). Parameter optimization for spray-drying microencapsulation of jaboticaba (myrciaria jaboticaba) peel extracts using simultaneous analysis of responses. Journal of Food Engineering, 117(4), 538-544. http://dx.doi.org/10.1016/j.jfoodeng.2012.08.039.

Simon-Brown, K., Solval, K. M., Chotiko, A., Alfaro, L., Reyes, V., Liu, C., Dzandu, B., Kyereh, E., Goldson Barnaby, A., Thompson, I., Xu, Z., \& Sathivel, S. (2016). Microencapsulation of ginger (zingiber officinale) extract by spray drying technology. Lebensmittel-Wissenschaft + Technologie, 70, 119-125. http://dx.doi.org/10.1016/j.lwt.2016.02.030.

Venil, C. K., Khasim, A. R., Aruldass, C. A., \& Ahmad, W. A. (2016). Microencapsulation of flexirubin-type pigment by spray drying: characterization and antioxidant activity. International Biodeterioration \& Biodegradation, 113, 350-356. http://dx.doi.org/10.1016/j. ibiod.2016.01.014. 